\title{
CARACTERIZAÇÃO DA BACIA DO RIO QUILOMBO, RJ: ESBOÇO DAS INFLUÊNCIAS GEOLÓGICAS E GEOMORFOLÓGICAS NO SISTEMA DE DRENAGEM
}

\author{
Rodrigo Wagner Paixão Pinto ${ }^{(a)}$, Stephany Emiliane Lopes Silva ${ }^{(b)}$, Raphaela Almeida de \\ Souza $^{(\mathrm{c})}$, Marcelo Motta de Freitas ${ }^{(\mathrm{d})}$ \\ (a) Departamento de Geografia/PUC-Rio (rodrigowpp1 @ gmail.com) \\ (b) Departamento de Geografia/PUC-Rio (stephany-emiliane @ hotmail.com) \\ (c) Departamento de Geografia/PUC-Rio (raphaelaalmeidas@yahoo.com.br) \\ (d) Departamento de Geografia/PUC-Rio (marcelomotta@puc-rio.br)
}

\section{Eixo: SISTEMAS GEOMORFOLÓGICOS: ESTRUTURA, DINÂMICAS E PROCESSOS}

\begin{abstract}
Resumo/
O presente trabalho objetiva analisar os condicionantes geológicos e geomorfológicos na configuração do sistema de drenagem da bacia do Ribeirão do Quilombo. A bacia do Ribeirão do Quilombo localiza-se no Planalto Sudeste Brasileiro abrangendo parte de 3 municípios, da região serrana do estado do Rio de Janeiro, sendo eles: Carmo, Duas Barras e Cantagalo. Foi utilizada a bacia de drenagem como unidade de escala, uma vez que, no entendimento dos processos hidrológicos e erosivos, a bacia de drenagem constitui-se na unidade de análise da paisagem e, a partir dela, foram desenvolvidos os mapeamentos e análises. Os lineamentos estruturais predominantes na bacia em estudo estão orientados, principalmente, para NW, contudo são observados lineamentos em outras direões, em especial, para NE. Esta característica influencia na orientação da rede de drenagem, cujos canais principais ocorrem em vales alargados para NE, com presença de alvéolos sedimentares.
\end{abstract}

Palavras chave: Ribeirão do Quilombo; sistemas de drenagem; condicionantes geológicos e geomorfológicos.

\section{Introdução}

Entender a evolução geomorfológica da paisagem remete-nos, também, ao entendimento dos sistemas de drenagem, pois, os mesmos trazem consigo características intrínsecas à história de evolução da paisagem. A conformação, arranjo e distribuição dos canais fluviais tornam-se fundamentais para a junção dos episódios evolutivos que modelaram e moldam a superfície terrestre (SILVA \& SANTOS, 2010). Neste sentido, a identificação de anomalias, tais como, mudanças abruptas nas direções dos cursos d'água constituem uma ferramenta importante para a reconstituição paleogeográfica da rede de drenagem e, portanto, da evolução do relevo.

Uma das formas de compreender a evolução geomorfológica da paisagem se dá pelo reconhecimento dos sucessivos ciclos alternados de agradação e degradação do relevo. A alternância destes ciclos foi identificada através de análises estratigráficas, tanto em depósitos fluviais de fundos de vale como em 
colúvios localizados nas encostas (LEOPOLD et al., 1964; MEIS \& MONTEIRO, 1979). A reconstituição de eventos erosivo-deposicionais durante o Quaternário, principalmente, no Planalto Sudeste Brasileiro tem sido objeto de estudo por diferentes abordagens e pesquisadores (BIGARELLA \& MEIS, 1965; MOURA \& MEIS, 1980; SILVA, 1991; SILVA et al., 2006; RICCOMINI et al., 2010).

O relevo da região foi bastante influenciado por esforços tectônicos durante o ciclo brasiliano pelo amalgamento de placas e, posteriormente, pela abertura do Rift Continental do Sudeste do Brasil (RCSB) durante o Paleógeno (AB'SABER, 1957; RICCOMINI et al., 2010). Estes movimentos resultaram em estruturas, tanto dúcteis quanto rúpteis, que foram de extrema importância na configuração atual do relevo da Região Sudeste do Brasil como demonstrado por Ruellan (1944) ao analisar a evolução geomorfológica da Baía de Guanabara. Diferentes estudos abordam as transformações na paisagem do Planalto Sudeste Brasileiro, tanto através dos eventos tectônicos ocorridos no final do Cretáceo, quanto pela interpretação estratigráfica de depósitos e mudanças climáticas durante o Quaternario (FERRARI, 2001; COELHO NETTO, 2003;).

A quebra do continente Gondwana e seus múltiplos eventos até a consolidação do RCSB implicou em uma mudança significativa no relevo e, consequentemente, nos sistemas de drenagens (RICCOMINI et al., 2010). Uma das principais características desses eventos são as reativações de estruturas brasilianas, bem como, o soerguimento e abatimento de blocos crustais. Isto promoveu a reorganização dos sistemas de drenagens e uma nova dinâmica hidroerosiva pelo rebaixamento do nível de base no setor leste do continente com a consolidação dos Riftes Cenozoicos do Sudeste do Brasil. (ZALÁN \& OLIVEIRA, 2005; RICCOMINI et al., 2010).

Diversos autores chamam atenção para o sistema de capturas do rio Paraíba do Sul dos sistemas fluviais da região Sudeste, associados à quebra do supercontinente Gondwana, formação do RCSB e rebaixamento do nível de base. Neste sentido, destaca-se a captura do Alto Tietê pelo rio Paraíba do sul (AB'SABER, 1957; CHRISTOFOLETTI, 1977; OLIVEIRA, 2003). O mesmo pode ter ocorrido para os cursos d'água que, atualmente, drenam para este rio e, preteritamente, apresentavam outra conformação dos sistemas fluviais e drenavam para paleobacias. Sobre a dinâmica de capturas, estudos como o de Ab'Saber (1957), Oliveira (2003), Cheremet al. (2012), Pasa (2013) dentre outros demonstram o avanço do sistema de drenagem do rio Paraíba do Sul em detrimento das bacias adjacentes, como a do rio Paraná, rio São Francisco e rio Doce.

Um dos fatores que influenciam nas capturas de drenagem, são os níveis de base ou knickpoints, que influenciam diretamente na dinâmica erosiva da drenagem. Os níveis de base são considerados os degraus topográficos na paisagem ao longo de um perfil longitudinal de um rio e são feições de extrema importância no entendimento da dinâmica evolutiva de uma bacia de drenagem. Estes degraus podem ter 
origens distintas condicionadas pelas variações climáticas ou aos eventos tectônicos, sendo difícil definir precisamente a origem de cada knickpoint devendo levar em consideração às diferenças litológicas e às capturas fluviais que, também, dão origem a esta feição (SILVA et al. 2006).

Diante do exposto, selecionou-se como estudo de caso a bacia do Ribeirão do Quilombo no Rio de Janeiro por ser um dos afluentes do rio Paraíba do Sul e estar diretamente associado aos eventos tectônicos mencionados anteriormente que influenciaram o relevo da região. A bacia em estudo situa-se no reverso da Serra do Mar e, através da tectônica cenozoica e a consolidação do RCSB, pode ter sofrido mudanças significativas na estrutura e arranjo da dinâmica hidrológica da região, afetada por pulsos erosivos ao longo do tempo. Objetiva-se, analisar a rede de drenagem através da sua configuração, conformação, ordenamento e direção e identificar seus condicionantes geológicos e geomorfológicos através do mapeamento de feições e correlação de dados qualitativos.

\section{2. Área de Estudo}

A bacia do Ribeirão do Quilombo localiza-se no Planalto Sudeste Brasileiro abrangendo parte de três municípios da região serrana do estado do Rio de Janeiro, sendo eles: Carmo, Duas Barras e Cantagalo. O ribeirão do Quilombo pode ser caracterizado como uma drenagem afluente do Rio Paraíba do Sul, tendo suas nascentes em aproximadamente 880 metros de altitude e sua foz se dá na cota de 100 metros, próximo à divisa entre o município de Carmo e Cantagalo (Figura 1).

O clima da região é o tropical úmido que se caracteriza por duas estações bem definidas. No verão há concentração das chuvas, enquanto que no inverno ocorre período de estiagem. A precipitação média anual é de aproximadamente $1.200 \mathrm{~mm}$ e as temperaturas médias ficam entre $20^{\circ}$ e $25^{\circ}$ (LUMBRERAS, et al., 2003).

\section{Procedimentos Metodológicos}

Através do método hipotético-dedutivo, utilizou-se como base para a realização do trabalho o levantamento de informações bibliográficas, análises em ambiente SIG e elaboração de mapas.

Para este trabalho, foi utilizada a bacia de drenagem como unidade de escala, uma vez que, no entendimento dos processos hidrológicos e erosivos, a bacia de drenagem constitui-se na unidade de análise da paisagem, pois segundo Coelho Netto (1994) caracteriza um sistema hidrogeomorfológico, onde as mudanças de ordem natural ou antrópicas que operam no fornecimento de energia causam um reajuste nas formas e processos, de acordo com suas intensidades. 


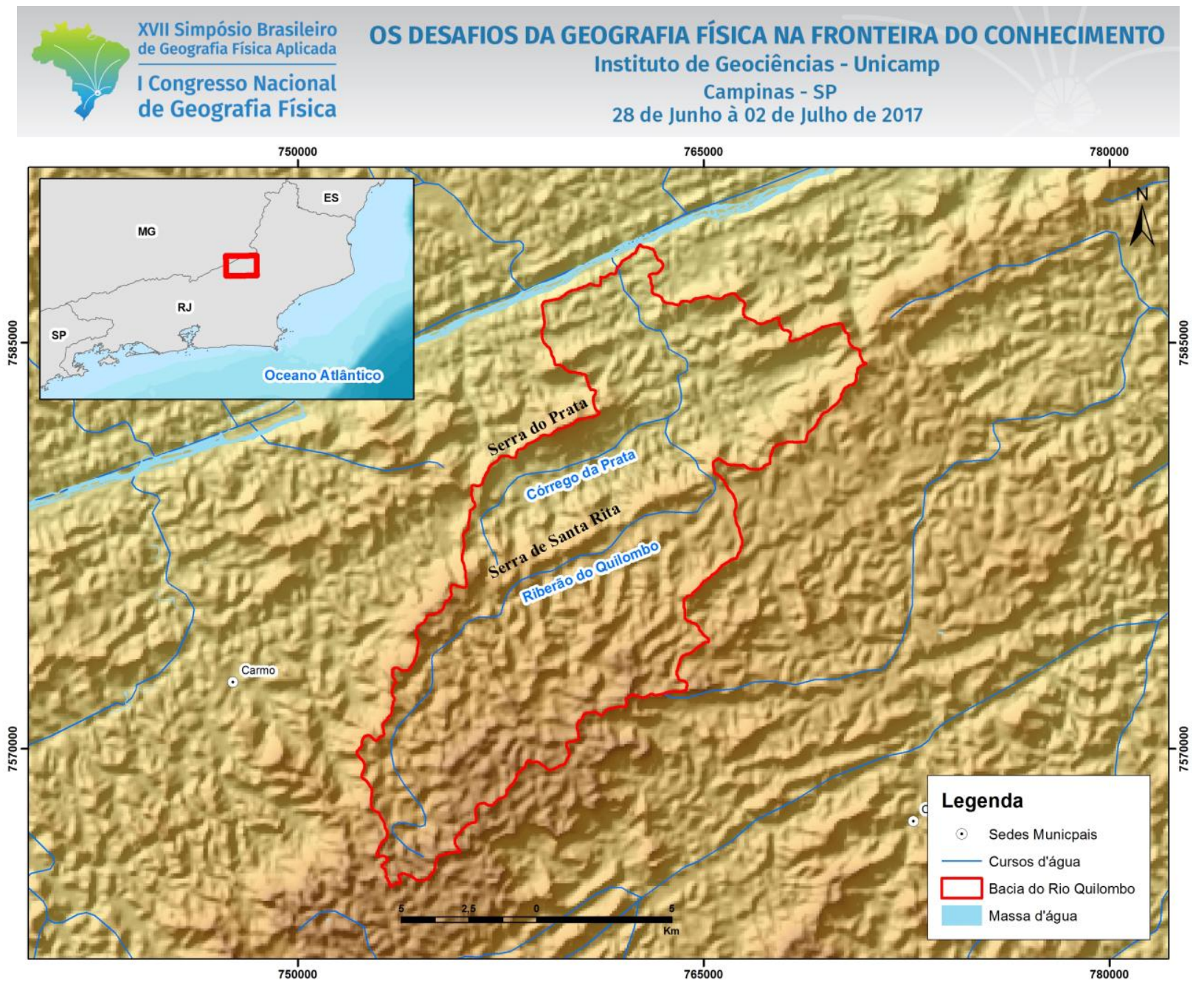

Figura 1: Localização da Bacia do Ribeirão do Quilombo.

Os procedimentos para os mapeamentos foram elaborados a partir da base cartográfica do IBGE na escala de 1:50.000 para a região. Neste sentido, foram utilizadas as cartas topográficas inseridas na área da bacia, totalizando duas cartas, sendo elas: Além Paraíba e Cantagalo. Além da base cartográfica do IBGE, as imagens de radar SRTM (Shuttle Radar Topography Mission) da NASA que foram ajustadas e corrigidas por pesquisadores da EMBRAPA (MIRANDA, E. E. et al., 2005) auxiliaram na elaboração dos mapeamentos.

Para a delimitação da bacia de drenagem, utilizou-se a base topográfica na escala de 1:50.000 do IBGE através do Arcgis. Este procedimento se deu, pela marcação da linha de cumeada ou divisores de drenagem, a partir de sua foz, até ser delimitado todo o sistema de drenagem da bacia do Ribeirão do Quilombo.

Os níveis de base, ou knickpoints, foram identificados através da análise das curvas de nível extraídas das cartas topográficas do IBGE na escala de 1:50.000 utilizando o software Arcgis. A delimitação dessa feição geomorfológica se deu nos locais onde há uma concentração de curvas de nível que caracterizam um desnível topográfico abrupto e, também, quando as mesmas se aproximam formando um 
estrangulamento seguido de desnível para jusante. Após o mapeamento dos níveis de base em ambiente digital.

A demarcação dos alvéolos acompanhou basicamente a mesma lógica do mapeamento das concavidades, porém, os alvéolos são identificados por outro tipo de formato. Esta feição do relevo corresponde à zona central do alargamento das curvas de nível, limitado entre as primeiras curvas. Neste mapeamento é utilizada imagem de satélite, pois, em alguns casos os alvéolos são mais estreitos que esta zona alargada entre as curvas de nível.

\section{Caracterização Geológica da Bacia do Ribeirão do Quilombo}

Em relação à geologia, a região estudada situa-se na Faixa Ribeira cuja formação é atribuída ao Neoproterozoico (HEILBRON et al., 2004; TUPINAMBÁ et al., 2012) no ciclo termotectônico de caráter dúctil denominado Brasiliano na configuração do supercontinente Gondwana acarretou em um complexo cinturão de dobramentos e empurrões na atual margem do sudeste brasileiro. A Faixa Ribeira é divida em quatro terrenos tectonoestratigráficos imbricados para NW/W em direção ao Cráton de São Francisco, sendo eles: Terreno Ocidental,Terreno Paraíba do Sul,Terreno Oriental e Terreno Cabo Frio (HEILBRON et al., 2004; TUPINAMBÁ et al., 2012). Em termos estruturais tal processo colisional leva as unidades litológicas a um alinhamento de orientação NE, justamente paralelo à direção da colisão. Após estabilidade crustal de aproximadamente 300 milhões de anos, ocorreram novos esforços tectônicos associados à abertura do oceano Atlântico que culminou em padrões de fraturamentos alinhados nas orientações N-S, NE-SW (HEILBRON et al., 2004).

Em relação às unidades geológicas identificadas na bacia, cabe ressaltar a presença de rochas de idade, em sua maioria, Neoproterozoicas, marcadas principalmente por Ortognaisses. As unidades que ocorrem na bacia em estudo são: Unidade Juiz de Fora, Unidade Andrelândia (granada-biotita gnaisse), Camada Andrelândia (quartzito), Unidade Andrelândia, Suíte Cordeiro, Complexo Serra da Bolívia, Depósitos Quaternários, Complexo Rio Negro e Unidade Arcádia Areal. Estas duas últimas unidades são as mais comuns na bacia do Ribeirão do Quilombo (Figura 2). 

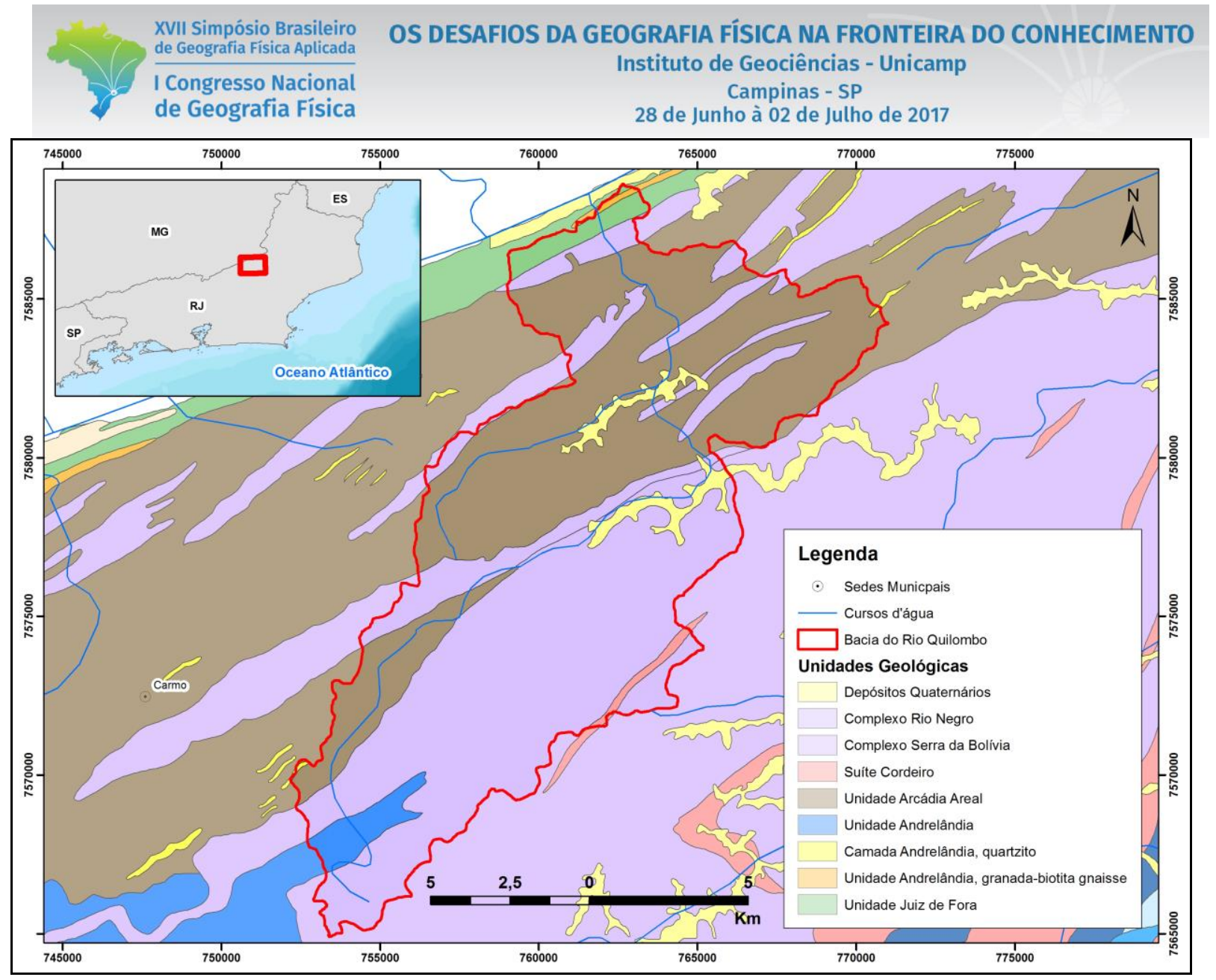

Figura 2: Unidades Geológicas na Bacia do Ribeirão do Quilombo. Fonte: Adaptado PRONAGEO.

Através do mapeamento foi possível perceber que a maioria dos contatos litológicos ocorrem na direção NE-SW e que influenciou na formação de lineamentos estruturais nesta orientação, como será abordado posteriormente. Esta característica pode ser observada na porção central da bacia, formando a Serra de Santa Rita e, próximo ao Rio Paraíba do Sul na formação da Serra do Prata.

\section{Lineamentos Estruturais e Orientação de Drenagem}

Em relação aos lineamentos, pode-se dizer que são encontrados em praticamente todas as direções sendo os de maior destaque aqueles de direções NW-SE e WNW-ESE, apesar disso, vale destacar que lineamentos NE-SW também são muito marcantes na bacia do Ribeirão do Quilombo (Figura 3). Os lineamentos estruturais para NE-SW são condicionados, em sua maioria, por estruturas regionais dúcteis como a foliação e dobras que ocorrem na área de estudo, com plano-axial de N40E (TUPINAMBÁ, et al. 2012). Além disso, como dito anteriormente, os contatos litológicos das unidades identificadas na bacia, contribuem para a formação de lineamentos na orientação NE-SW. Apesar do predomínio de estruturas 


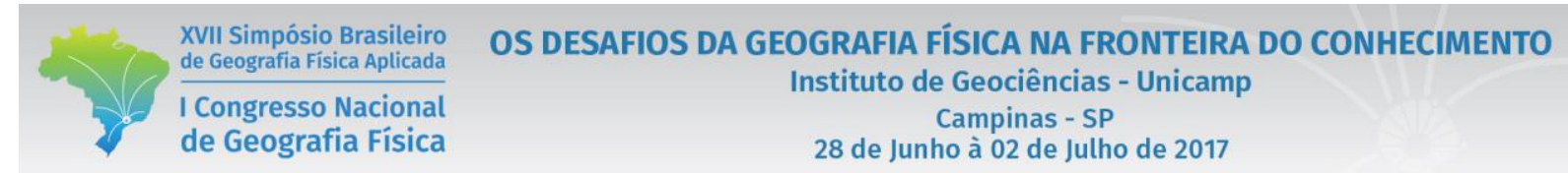

nas direções NW-SE nota-se que esses lineamentos possuem extensão relativamente pequenas quando comparados às direções NE-SW (Figura 4).

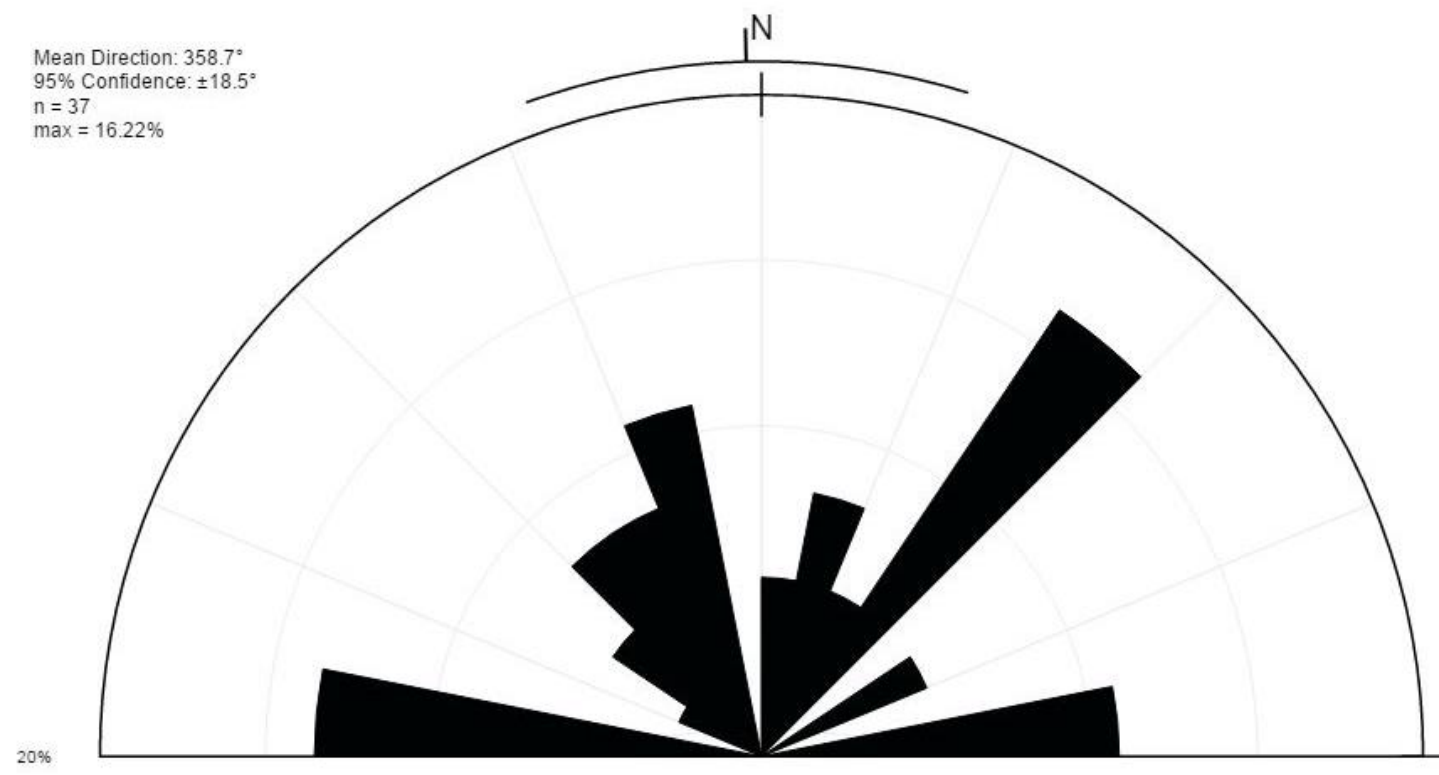

Figura

3: Roseta contendo a frequencia dos lineamentos estruturais da bacia do Ribeirão do Quilombo, desenvolvido no software Stereonet.

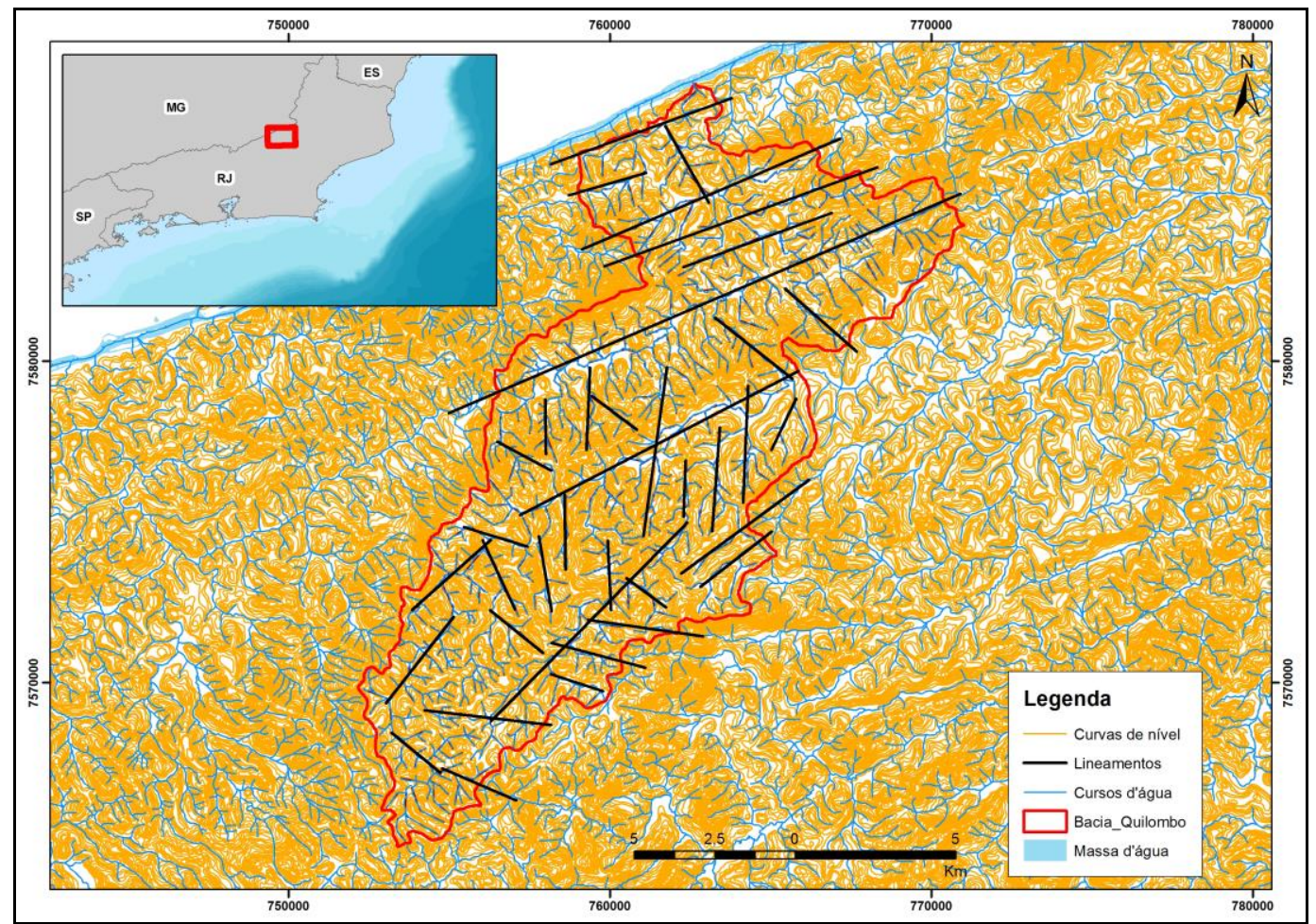

Figura 4: Mapa com a distribuição espacial dos lineamentos estruturais da bacia do Ribeirão do Quilombo. 
O Ribeirão do Quilombo inicia seu curso com direção de fluxo para noroeste, apresentando inflexões para norte e posteriormente para nordeste. A partir daí, a calha principal do Ribeirão do Quilombo apresenta diversas inflexões na orientação da drenagem. Ao atingir a cota de 550m aproximadamente, o Ribeirão do Quilombo apreende um vale de Santa Rita da Floresta, sendo este, uma das principais evidências do controle estrutural na rede drenagem. O vale, apesar de alargado, possui drenagem marcante para NE, beirando a Serra de Santa Rita até apresenta inflexão para NW em trecho bastante íngreme. À jusante deste trecho pode-se observar o vale do Córrego da Prata, bastante alargado orientado para NE, consideravelmente a rede de drenagem, exceto às drenagens que nascem nas Serra de Santa Rita e Serra do Prata. Estes vales orientados para NE exercem função de grandes coletores da rede de drenagem da bacia em estudo. A orientação da rede drenagem reflete este comportamento, onde os canais principais e mais extensos possuem orientação para NE enquanto que as drenagens mais curtas variam a direção para NW, N, S, SE. Apesar disso, a frequência das drenagens mais curtas é maior que os canais principais para NE, como pode ser observada na roseta a seguir. (Figura 5).

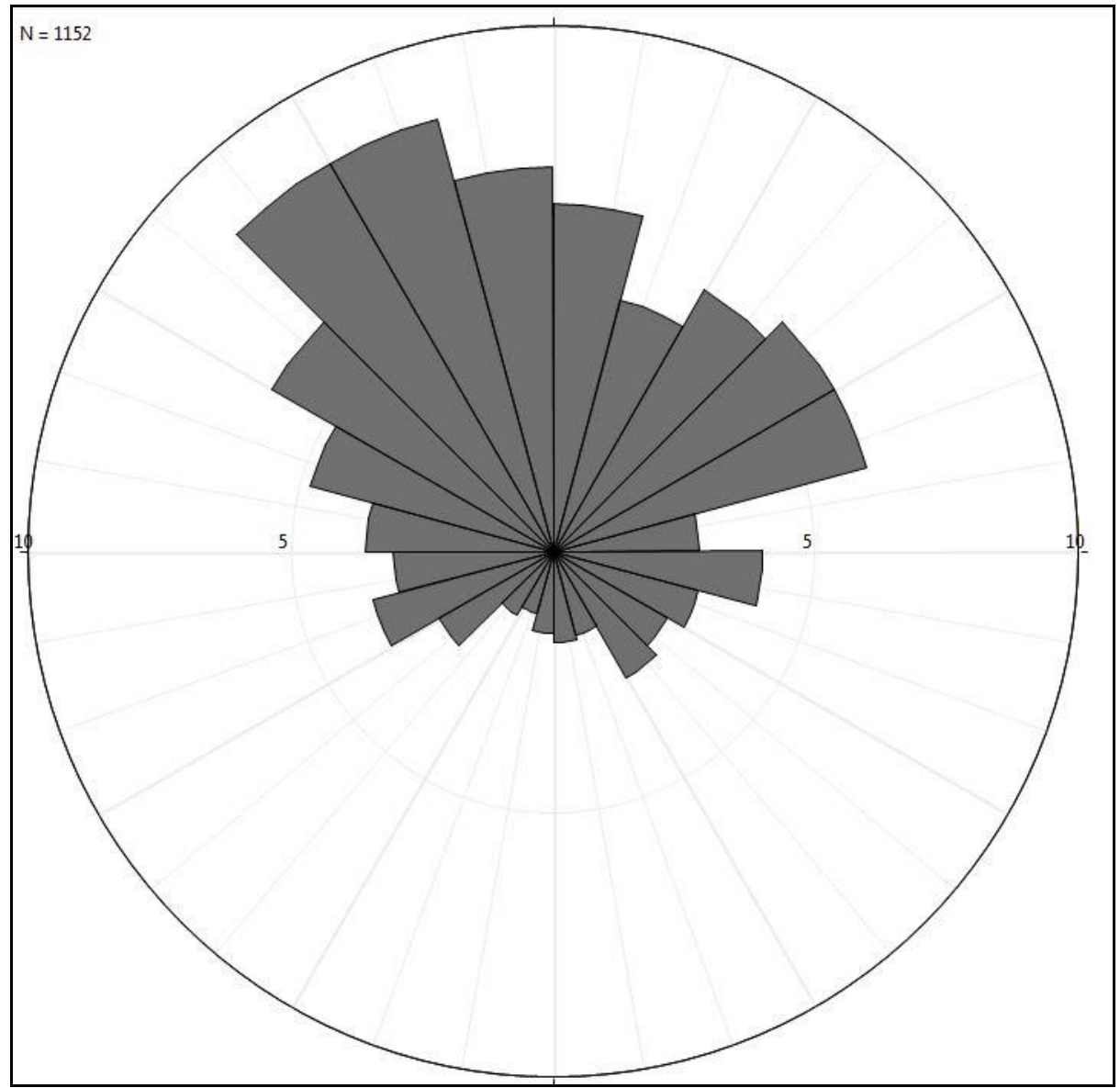

Figura 5: Roseta com a frequência da orientação da rede de drengam da bacia do Ribeirão do Quilombo. 


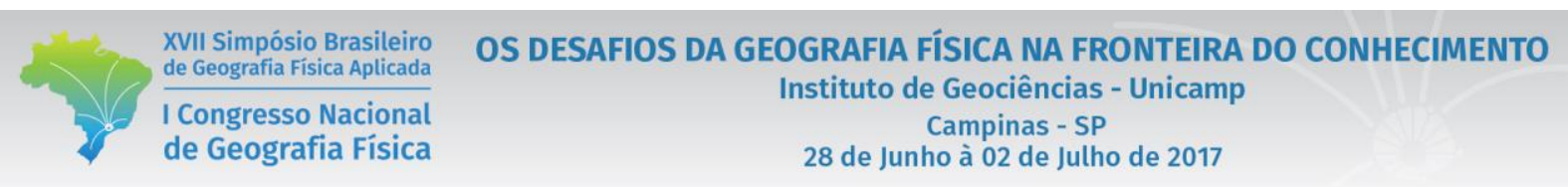

\section{Níveis de Base (knickpoints) e Alvéolos}

Foram identificados, através do mapeamento 79 knickpoints, ou níveis de base em toda a bacia do Ribeirão do Quilombo. Esta feição geomorfológica tem fundamental importância na dinâmica hidroerosiva da bacia. Ao analisar a distribuição espacial dos mesmos, percebe-se que não há uma correlação direta na sua gênese com a geologia, contudo, é possível identificar a formação de níveis de base próximos à contatos litológicos. Isto pode ser explicado pela erosão diferencial que as rochas apresentam. Além disso, pode-se destacar a ocorrência de pelo menos três níveis de base que configuram patamares topográficos na bacia. Já os alvéolos, restringem-se, principalmente, nos canais principais orientados para NE, com destaque para o alvéolo formado no vale de Santa Rita da Floresta e no Córrego da Prata. Próximo à foz com o Rio Paraíba do Sul, esta feição geomorfológica é bastante comum, principalmente pela elevada taxa de sedimentação do relevo (Figura 6).

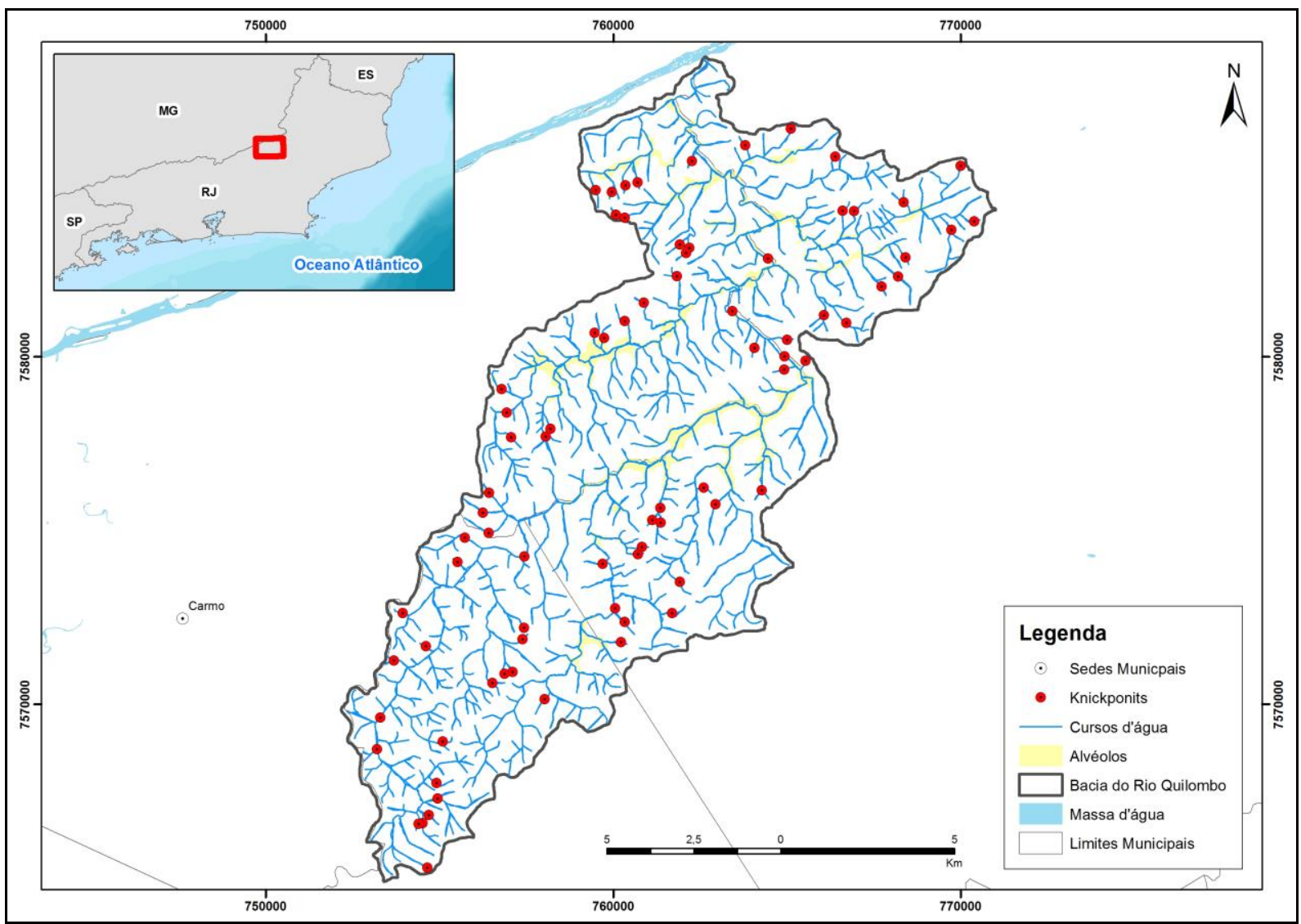

Figura 6: Distribuição espacial dos alvéolos e knickpoints na bacia do Ribeirão do Quilombo. 


\section{Considerações Finais}

Os eventos geológicos que ocorreram no Planalto Sudeste, desde a orogenia brasiliana até a consolidação dos Riftes Cenozoicos do Sudeste do Brasil influenciou sobremaneira no ordenamento dos sistemas de drenagens da região, o que pode ser observado na bacia do Ribeirão do Quilombo.

A conformação dos contatos litológicos para NE foram de fundamental importância na formação de lineamentos estruturais, como demonstrou a análise das características topográficas e da confecção da roseta de orientação. Isto pode ser explicado pela característica da Faixa Móvel Ribeira através de estruturas dúcteis, como a foliação, orientada neste mesma direção. Por sua vez, esta característica influenciou diretamente na orientação dos fluxos da rede drenagem, principalmente, na formação dos canais principais com vales alargados com orientação para NE.

Já o mapeamento de níveis de base, ou knickpoints, evidenciou a estruturação do relevo em três 3 patamares topográficos, fazendo a drenagem do Ribeirão do Quilombo, drenar sobre planaltos intermontanos separados por níveis de base, sendo eles, de montante para jusante: o primeiro próximo à localidade de Santa Rita da Floresta na inflexão para NW da rede de drenagem; o segundo próximo à confluência do Ribeirão do Quilombo com o Córrego da Prata; e o terceiro até sua confluência com o Rio Paraíba do Sul.

Cabe ressaltar que a formação dos alvéolos pode ser influenciada pelos lineamentos estruturais para NE, que promovem zonas de fraqueza na região, facilitando o alargamento e sedimentação dos vales. Além disso, a ocorrência dos níveis de base é de fundamental importância para a formação dos alvéolos, através do barramento dos sedimentos carreados no sistema de drenagem pela perda da energia de transporte.

Por fim, acredita-se que novos trabalhos devem ser realizados para análise das anomalias de drenagem e evidenciar com maior detalhamento as influências dos eventos tectônicos no sudeste brasileiro no ordenamento dos rios, não só para a bacia do Ribeirão do Quilombo, como para bacias da região.

\section{Bibliografia}

AB'SABER, A. N. O problema das conexões antigas e da separação da drenagem do Paraíba e do Tietê. Geomorfologia 26. São Paulo, Instituto de Geografia da USP, p. 38-49. 1957.

BIGARELLA, J.J. \& MEIS, M.R. M. Considerações a respeito dos terraços fluviais, rampas de colúvios e várzeas. Boletim Paranaense de Geografia, Curitiba. 16/17: 153-197, 1965.

CHEREM, L. F. S.; VARAJÃO, C. A. C.; BRAUCHER, R.; BOURLÉS, D.; SAlGADO, A. A.; VARAJÃO, A. C. Long-term evolution of denudational escarpments in southeastern Brazil. Geomorphology. v. 173-4. p. 118-27. 2012.

CHRISTOFOLETTI, A. Considerações sobre o nível de base, rupturas de declive, capturas fluviais e morfogênese do perfil longitudinal. Geografia, 2 (4), p. 81-102. 1977. 
COELHO NETTO, A.L. Hidrologia de Encostas na Interface com a Geomorfologia. In: GUERRA, A.J.T. e CUNHA,S.B. (Org.). Geomorfologia: Uma Atualização de Bases e Conceitos; Rio de Janeiro: Bertrand Brasil, pp. 93-148. 1994.

FERRARI, A. L. Evolução tectônica do Gráben da Guanabara. Tese (Doutorado), Instituto de Geociências, Universidade de São Paulo.p.412. 2001.

HEILBRON,M., PEDROSA-SOARES,A.C., CAMPOS NETO,M.C., SILVA,L.C., TROUW, R.A.J.; JANASI,V.A., Província Mantiqueira. In: MANTESSO-NETO,V. BARTORELLI,A., CARNEIRO,C.D.R. e BRITO-NEVES,B.B., Orgs. Geologia do Continente Sul-Americano: evolução da obra de Fernando Flávio Marques de Almeida. São Paulo, Ed. Beca, p.203-236. 2004.

LEOPOLD, L. B.; WOLMAN, M. G.; MILlER, J. P. Fluvial Processes. In Geomorphology. San Francisco. W. H. Freeman Co, 1964. p. 522.

LUMBRERAS, J. F. (Org) Zoneamento Agroecológico do Estado do Rio de Janeiro. Rio de Janeiro: EMBRAPA Solos. Boletim de Pesquisa e Desenvolvimento; n. 33. 2003.

MEIS, M.R.M. \& MONTEIRO, A.M.F. Upper Quaternary rampas: Doce rivervalley, SE Brazilian Plateau. Zeit. Geomorph., 23: 132- 151. 1979.

MIRANDA, E. E. de; (Coord.). Brasil em Relevo. Campinas: Embrapa Monitoramento por Satélite, 2005. Disponível em: <http://www.relevobr.cnpm.embrapa.br>. Acesso em: 15 jun. 2013.

MOURA, J. R. S.\& MEIS, M. R. M. Litoestratigrafia preliminar para os depósitos de encosta do Quaternário Superior do Planalto SE do Brasil (MG-RJ). Rev. Bras. Geoc., 10(4):258-267. 1980.

OLIVEIRA, D. A captura do Alto Rio Guaratuba: uma proposta metodológica para o estudo da evolução do relevo na Serra do Mar, Boracéia-SP. 105f.+anexos. Tese (Doutorado) - Departamento de Geografia-FFLCHUSP, São Paulo. 2003.

PASA, VANIZA. Estudo da Conexão entre as drenagens do Médio Paraíba do Sul e do Alto Tietê: O caso do cotovelo de Guararema-SP, Brasil. Dissertação (Mestrado). Departamento de Geografia, Universidade de São Paulo, São Paulo. 110 p. 2013

RICCOMINI, C.; GROHMANN, C. H.; SANT'ANNA, L. G.; HIRUMA, S. T. A Captura das Cabeceiras do Rio Tietê pelo Rio Paraíba do Sul. In: MONDENSEI-GAUTTIERI, M. C.; BARTORELLI, A. CARNEIRO, C. R. LISBOA, M. B. A. L. A Obra de Aziz NacibAb'Sáber. São Paulo: Beca-BALL edições, 2010.

SILVA, T.M. Evolução Geomorfológica e Sedimentação de Canais Erosivos Holocênicos no Médio Vale do Rio Paraíba do Sul. Programa de Pós-Graduação em Geografia, Universidade Federal do Rio de Janeiro, Dissertação de Mestrado, 165p. 1991.

SILVA, T.M.; MONTEIRO, H.S.; CRUZ, M.A.; MOURA, J.R.S. Anomalias de drenagem e evolução da paisagem no médio vale do rio Paraíba do Sul (RJ/SP). Anuário do Instituto de Geociências (Rio de Janeiro), v. 29, p. 210-224. 2006

SILVA, T. M.; SANTOS, B. P. Sistemas de Drenagem e Evolução da Paisagem. Revista Geogr. Acadêmica v.4, n.1, 5-19. 2010.

TUPINAMBÁ, M.; TEIXEIRA, W.; HEILBRON, M. Evolução Tectônica e Magmática da Faixa Ribeira entre o Neoproterozoico e o Paleozoico Inferior na Região Serrana do Estado do Rio de Janeiro, Brasil. Anuário do Instituto de Geociências - UFRJ. Vol. 35 - 2, p.140-151. 2012.

ZALÁN, P. V.; OLIVEIRA, J. A. B. Origem e evolução estrutural do Sistema de Riftes Cenozóicos do Sudeste do Brasil. Boletim de Geociências Petrobras, Rio de Janeiro, v. 13, n. 2, p. 269-300, maio/nov. 2005. 